\title{
Local Climate Sensitivity of the Three Gorges Dam
}

Norman L. Miller, Jiming Jin, and Chin-Fu Tsang

Earth Sciences Division, Berkeley National Laboratory

\begin{abstract}
Two simulations, control and land use change, were performed for an eight week period (2 April - 16 May 1990) to determine the net sensitivity of the local climate around the Three Gorges Dam. The analysis indicates that the large reservoir acts as a potential evaporating surface that decreases the surface temperature, cools the lower atmosphere, decreasing upward motion, and increasing sinking air mass. Such sinking results in low level moisture divergence, decreasing cloudiness, and increasing net downward radiation, which increases the surface temperature. However, results indicate that evaporative cooling dominates radiative warming in this initial study. The strong evaporation also supplies moisture to the atmosphere, suggesting an increase in precipitation, but the sinking moist air diverges away from the TGD region with no net change in precipitation. This numerical study represents an initial methodology for quantification of the impact of the Three Gorges Dam on the local climate and a more comprehensive, fine-scale set of multi-season simulations with additional observational data is needed for a more complete analysis.
\end{abstract}

\section{Introduction}

The impacts of land use change on weather and climate have received increasing attention (e.g. Cotton and Pielke 1992, Vorosmarty et al. 1998, Xue and Fennessy 2002). Research on the impacts of deforestation of the Brazilian Amazon rainforest on climate have indicated that the local region will lose moisture stored in broad leaves, causing a decrease in evaporation, and an increase in sensible heat and convective precipitation (Gash and Nobe 1997; Negri et al. 2004). In other locations, urban development has resulted in local heat islands (Taha 1997) and agriculture and overgrazing have caused a 
number of changes, including the surface roughness, evapotransporation, infiltration, and sensible heating rates (Pielke et al. 1991; CSCPRC 1992). These land use changes, along with man-made lakes and reservoirs, change the energy and water budgets, affect the regional weather and climate patterns, and frequently have wider impacts.

The Three Gorges Dam (TGD) on the Yangtze River in China represents the world's largest man-made reservoir, with an expected total storage capacity of 39.3 billion $\mathrm{m}^{3}$, a hydroelectric potential of 84.7 billion kilowatt hours and flood reduction in low lying regions downstream. By 2009, the TGD is expected to fully submerge a 663 $\mathrm{km}$ length of the Yangtze River and will have a $1040 \mathrm{~km}^{2}$ wet surface area, representing a significant land use change in topography and evaporation that is expected to result in changes in the regional weather and climate patterns. Previous studies by the Chinese Meteorological Institute (Qin and Peter 1992) suggest that the TGD reservoir area will alter local patterns of precipitation, wind, and temperature, and estimate that the annual average near surface air temperature in the vicinity of the TDG will increase by $0.3^{\circ} \mathrm{C}$. However, the local climatic impacts due to the change in surface area and weather patterns have not been systematically quantified and are not fully understood.

In this sensitivity study we consider the change in surface characteristics in the TGD area from one of steep vegetated terrain to a large flat saturated surface. This land use change represented here is the largest man made surface with a potential evaporating rate. Here, we investigate changes in local circulation patterns and seek to quantify the relative change in temperature, precipitation, and energy fluxes using a regional atmospheric model coupled to a land surface model.

The motivation of the present investigation is based in part on recent reports, including the estimated $0.3^{\circ} \mathrm{C}$ temperature increase (Qin and Peter 1992). To evaluate this finding, we obtained from the Chinese Ministry of Water Resources the 1984-2004 daily temperature observations from the Yichang Station, located at the Three Gorges Dam site. Figure 1 shows the mean April to August (AMJJA) maximum temperature $\left(\mathrm{T}_{\max }\right)$ trends at Yichang for 1984-1992, the period prior to filling, and 1992-2004, the period during filling. Based on this partial data set, an increasing April-August $\mathrm{T}_{\max }$ is seen for the pre-TDG filling, with an increasing slope of $0.053^{\circ} \mathrm{C} / \mathrm{AMJJA}$, while the 1992-2004 
period has a much flatter $\mathrm{T}_{\max }$ slope of $0.010^{\circ} \mathrm{C} / \mathrm{AMJJA}$. Additionally, the 1992-2004 period has significantly less variability, suggesting that the presence of the reservoir's thermal buffering capacity, as compared to the pre-THD land surface $\mathrm{T}_{\max }$ fluctuations. This partial result, which is counter to Qin and Peter (1992), motivated the present numerical sensitivity experiment to determine specifically, what levels of relative climate change might be expected in 2009 and beyond, when the TDG reservoir has been filled.

\section{Approach}

To quantitatively investigate the relative impact of the TGD land use change on the local climate, two regional climate model simulations, control and the TGD land use change, were generated for the period 2 April to 16 May 1990. This 44 day non-rain period was selected for analysis of the effects of this evaporating surface on the local weather patterns independent of large scale weather, such as monsoons.

The regional climate model used in this study is the non-hydrostatic version on the Penn State/National Center for Atmospheric Research Mesoscale Model Version 5 (MM5: Grell et al. 1994). MM5 was configured with 18 vertical layers, the Grell convection scheme to parameterize cumulus clouds (Grell 1993), and the Medium Range Forecast planetary boundary layer scheme to solve boundary layer processes (Hong and Pan 1996). The Oregon State University Land Surface Model (OSULSM; Pan and Mahrt 1987) coupled to MM5 by Chen and Dudhia (2001) was used to characterize land surface

processes. The OSULSM has 4 soil layers with a total depth of 2 meters and a vegetation scheme advanced by Chen et al (1996), with the canopy resistance approach of Noilhan and Planton (1989).

MM5 was configured with a $50 \mathrm{~km}$ spatial resolution with a one-way nested 10 $\mathrm{km}$ resolution grid. The $50 \mathrm{~km}$ domain coordinates are $70 \mathrm{E} 17 \mathrm{~N}$ by $140 \mathrm{E} 55 \mathrm{~N}$, and the $10 \mathrm{~km}$ resolution domain coordinates are $100 \mathrm{E} 26 \mathrm{~N}$ by $116 \mathrm{E} 34 \mathrm{~N}$. The land use change sensitivity carried out for the $10 \mathrm{~km}$ resolution nested simulation substituted the Yangtze River Valley area from Yichang to Chongqing with a flat saturated surface area of 1040 $\mathrm{km}^{2}$ (Fig. 2). The $50 \mathrm{~km}$ resolution MM5 simulation was initialized and the lateral boundaries were updated every 12 hours using the National Centers for Environmental Prediction/National Center for Atmospheric Research Reanalysis II (Reanalysis) data set. 
The MM5 $10 \mathrm{~km}$ resolution simulation used the $50 \mathrm{~km}$ output as input forcing, with $10 \mathrm{~km}$ output data archived at six hour intervals for analysis.

\section{Results}

The 2 April to 16 May 1990 time series of the $1040 \mathrm{~km}^{2}$ TGD area-averaged latent heat flux, sensible heat flux, surface skin temperature, and $2 \mathrm{~m}$ air temperature for the relative control and the land use change are shown in Fig. 3a-d. The latent heat flux for this 44 day simulation is consistently higher in the TGD simulation than the control, with values ranging from 15-135 W/m² (Fig. 3a). The 44-day mean difference is an increase of $79.6 \mathrm{~W} / \mathrm{m}^{2}$, with the largest differences occurring during the warmer days, as would be expected. The energy required for this increase in evaporation is removed from the surface, which lowers the temperature. The surface skin temperature decreased by $1^{\circ} \mathrm{C}$ to $4.5^{\circ} \mathrm{C}$, with a mean increase of $2.9^{\circ} \mathrm{C}$ (Fig. 3c). The $2 \mathrm{~m}$ air temperature change is less dramatic, with daily decreases ranging from $1^{\circ} \mathrm{C}$ to $2.5^{\circ} \mathrm{C}$, and a 44-day (Fig. 3d) mean decrease of $1.5^{\circ} \mathrm{C}$. These temperature differences drive the daily changes $\left(5-80 \mathrm{~W} / \mathrm{m}^{2}\right)$ in the sensible heat flux, where the control ranges from 5-80 W/m ${ }^{2}$ and the TGD change ranges from -45 to $20 \mathrm{~W} / \mathrm{m}^{2}$ (Fig. $3 \mathrm{~b}$ ). The 44-day mean change in the sensible heat flux is $-48.9 \mathrm{~W} / \mathrm{m}^{2}$. The diurnal latent and sensible heat fluxes are most pronounced at midday, with the TGD simulation of latent heat increasing by nearly $200 \mathrm{~W} / \mathrm{m}^{2}$ and the sensible heat flux decreasing by $50-75 \mathrm{~W} / \mathrm{m}^{2}$ (Fig. 4).

The overlying air becomes more stable and air mass aloft sinks. The $850 \mathrm{mb}$ vertical wind speed has a downward velocity exceeding $10^{-2} \mathrm{~m} / \mathrm{s}$ along the TGD area (Fig. 5). It is not clear if regions outside of this land use change with rising and sinking motion can be attributed to the TGD impact. To fully understand the spatial range of impact, a much longer simulation that represents a true climate is needed. It is interesting to note that the areas of maximum downward flow correspond to changes in topography from steep valleys to a flat surface. Figure 6 follows from these results indicating that the sinking air mass brings about a low level divergence of moisture away from the TGD. It can be seen that for areas of maximum downward velocity, the negative moisture flux divergence in the presence of the TGD is on the order $5-8 \times 10^{-8} \mathrm{~m} / \mathrm{s}$. This dries the air column above the TGD further, reducing cloudiness, and increasing net surface radiation. 
With a reduction in local clouds over TGD, the downward solar radiation increases by 5 to $25 \mathrm{~W} / \mathrm{m}^{2}$ (Fig. 7), but the downward longwave radiation decreases by about $1.5 \mathrm{~W} / \mathrm{m}^{2}$. This local radiation shift along Yangtze River valley is well demarcated and there are decreases just beyond the wetted surface area. This leaves an uncertain balance between evaporative cooling and radiative heating, where cooling appears to dominate during the 2 April to 16 May 1990 simulation period. These results are summarized in Table 1.

\section{Summary and Conclusion}

Two simulations, control and land use change, were performed for an eight week period (2 April - 16 May 1990) to determine the net sensitivity of the local climate. The analysis indicates that such a large reservoir acts as a potential evaporating surface that decreases the local surface temperature, and cools the entire atmospheric column, decreasing upward motion, resulting in sinking air. This sinking air mass causes low level moisture divergence, decreases cloudiness, and increases net downward radiation, which tends to increase the surface temperature. However, the evaporative cooling dominates radiative heating, and resulting in a net decrease in surface and $2 \mathrm{~m}$ air temperature. The strong evaporation pumps moisture into the atmosphere, which suggests an increase in precipitation, but the moisture divergence moves this away from the TGD region with no net change in precipitation.

The two processes, increased latent heating with surface cooling, and decreased cloudiness with increased downward solar radiation, are opposing feedbacks that are dominated here by the area-mean surface cooling effect. It is not clear if this holds true for other times of the year when the mean $\mathrm{T}_{\max }$ is lower and cloudiness may be higher. Furthermore, the impacts on the local monsoon flow, precipitation intensity, and frequency, have not been studied in this initial investigation. However, these relative changes are significant and will likely have an impact on local ecosystems, agriculture,

energy, and the population. Simulations at $10 \mathrm{~km}$ are not sufficiently fine enough to determine the full extent of this sensitivity and, hence, $1 \mathrm{~km}$ multi-year simulations will be needed. 
Acknowledgements: We thank the Chinese Ministry of Water Resources for providing the Yichang temperature observations. We appreciate the useful discussion based on this material when it was presented at the American Meteorological Society's 2005 Spring Conference in San Diego. This research was conducted under the auspices of the U. S. Department of Energy by the University of California, Lawrence Berkeley National Laboratory under contract DE-AC03-76F00098. This manuscript is Lawrence Berkeley National Laboratory Report Number XXXX.

\section{References}

Chen, F. and J. Dudhia, 2001: Coupling an advanced land-surface/hydrology model with the Penn State/NCAR MM5 modeling system. Part I: Model implementation and sensitivity. Mon. Wea. Rev., 129, 569-585.

Committee on Scholarly Communication with the People's Republic of China (CSCPRC), 1992: Grasslands and grassland sciences in northern China. National Academy Press, Washington, D.C., 214 pp.

Gash, J.H.C. and C.A. Nobre, 1997: Climatic effects of Amazonian deforestation: Some results from ABRACOS. Bull. Amer. Meteor. Soc., 78, 823-830.

Grell, G., 1993: Prognostic evaluation of assumptions used by cumulus parameterizations. Mon. Wea. Rev., 121, 764-787.

Grell, G., J. Dudhia, and D. Stauffer, 1994: A description of the fifth-generation Penn State/NCAR Mesoscale Model (MM5). NCAR Tech. Note NCAR/TN-398 + STR, 117 pp. Hong, S.-Y, and H.-L. Pan, 1996: Nonlocal boundary layer vertical diffusion in a mediumrange forecast model. Mon. Wea. Rev., 124, 2322-2339.

Negri, A.J., R.F. Adler, L. Xu, and J. Surratt, 2004: The impact of Amazonian deforestation on dry season rainfall. J. Climate, 17, 1306-1319.

Noilhan, J., and S. Planton, 1989: A simple parameterization of land surface processes for meterological models. Mon. Wea. Rev., 117, 536-549.

Pan, H.-L., and L. Mahrt, 1987: Interaction between soil hydrology and boundary-layer development. Boundary Layer Meteor, 38, 185-202. 
Pielke, R.A. and W.R. Cotton, 1992: Human Impacts on Weather and Climate. Cambridge Univ. Press. 288 pp.

Pielke, R.A., G. Dalu, J.S. Snook, T.J. Lee, and T.G.F. Kittel, 1991: Nonlinear influence of mesoscale landuse on weather and climate. J. Climate, 4, 1053-1069.

Qin, L. and G. Peter, 1992: Yangtze Project Dammed with Faint Praise. Nature. April 30.

Taha H., 1997: Urban Climates and Heat Islands: Albedo, Evapotranspiration, and Anthropogenic Heat, Energy \& Buildings, Special Issue on Urban Heat Islands, 25, 99-103.

Vorosmarty, C.J., C. Li, and Z. Dai, 1998: Drainage basins, river systems, and anthropogenic change: the Chinese example. In Asian Change in the context of Global Change. Ed. J. N. Galloway and J.M. Melillo, Cambridge Univ. Press, Ch. 9, 210-244.

Xue, Y. and M.J. Fenessy, 2002: Under what conditions does land-cover change impact regional climate?, Global Desertification: Do humans cause deserts?, Ed. J.F. Reynolds and D.M. Stafford Smith, Dahlem Univ. Press. 


\begin{tabular}{|c|c|}
\hline Surface skin temperature & $-2.9 \mathrm{C}$ \\
\hline 2m height air temperature & $-1.5 \mathrm{C}$ \\
\hline Precipitation & $0.003 \mathrm{~mm}$ \\
\hline Latent heat flux & $74.2 \mathrm{~W} / \mathrm{m}^{2}$ \\
\hline Sensible heat flux & $-48.9 \mathrm{~W} / \mathrm{m}^{2}$ \\
\hline Downward Longwave radiation & $-1.5 \mathrm{~W} / \mathrm{m}^{2}$ \\
\hline Downward Shortwave radiation & $12.8 \mathrm{~W} / \mathrm{m}^{2}$ \\
\hline
\end{tabular}

Table 1. Mean difference between the Change and Control

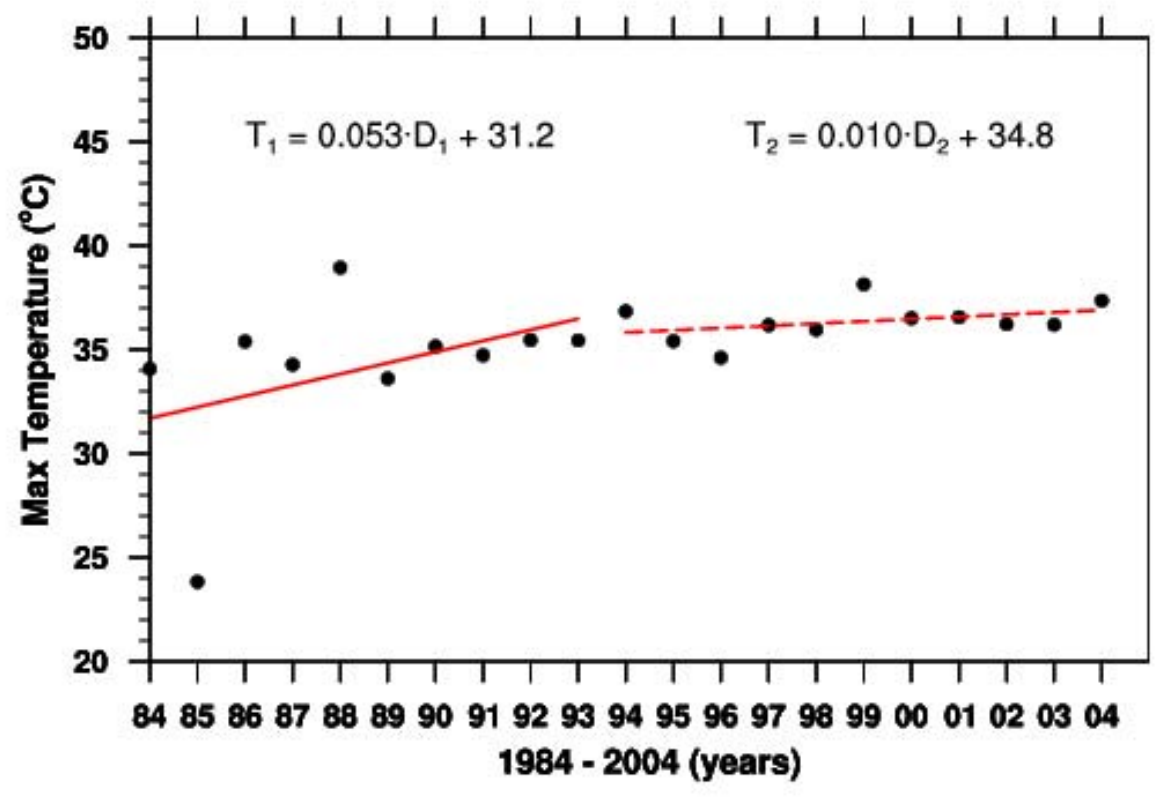

Figure 1. The 1984-1993 and 1994-2004 mean April-August $\mathrm{T}_{\max }$ trends indicate a shift in slope from 0.053 to 0.010 , and a decrease in $\mathrm{T}_{\max }$ variability. 


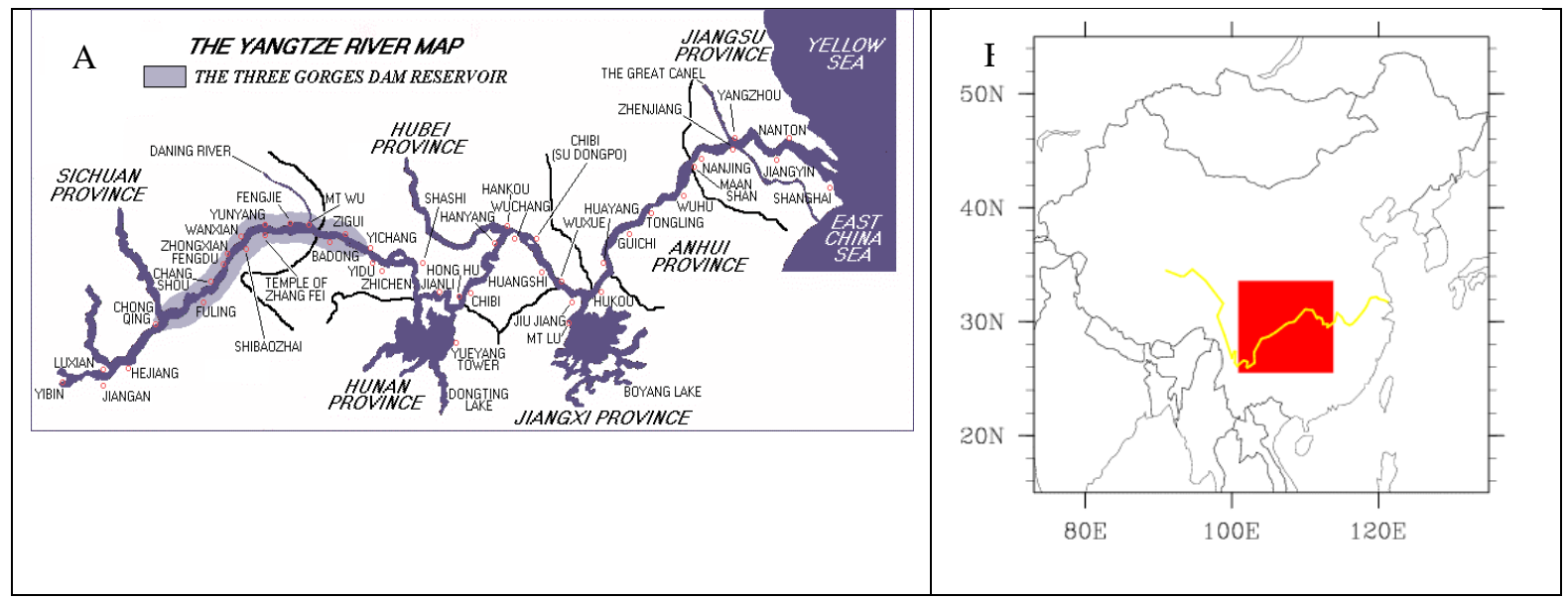

Figure 2. The Yangtze Valley River from Yichang to Chongqing (a) has been simulated as a flat surface within the $10 \mathrm{~km}$ resolution nested domain shown in (b). 


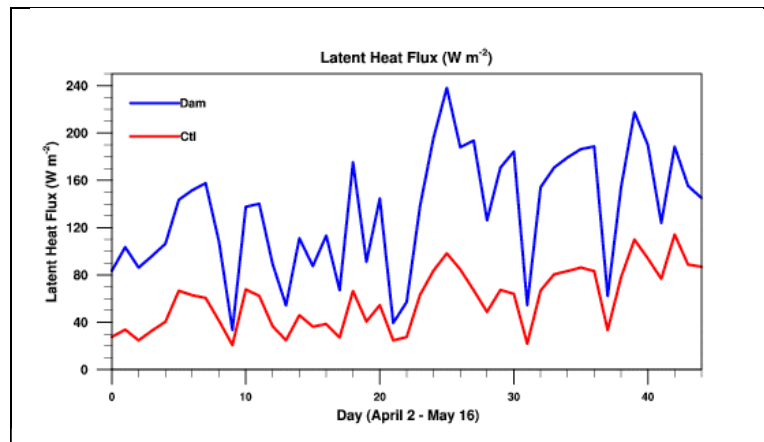

A

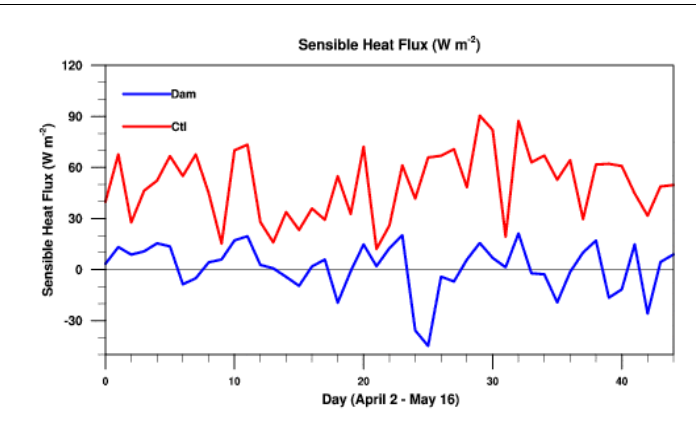

B

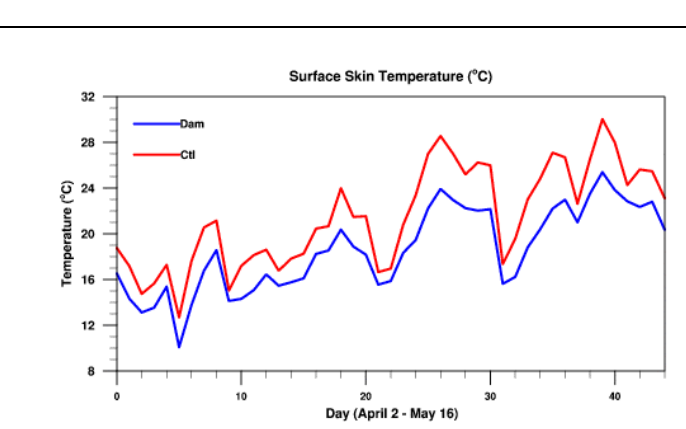

C

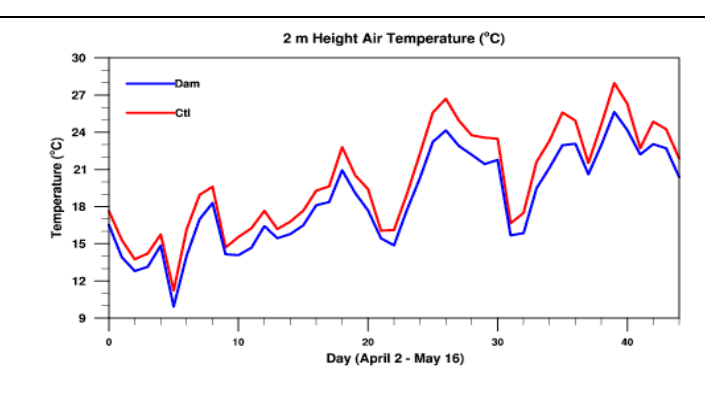

$\mathrm{D}$

Figure 3. MM5-simulations for 2 April - 16 May 1990 indicating a (A) Latent heat flux, (B) Sensible heat flux, (C) Surface skin temperature, and (D) $2 \mathrm{~m}$ air temperature, where the blue line is the simulated control and red is the change.

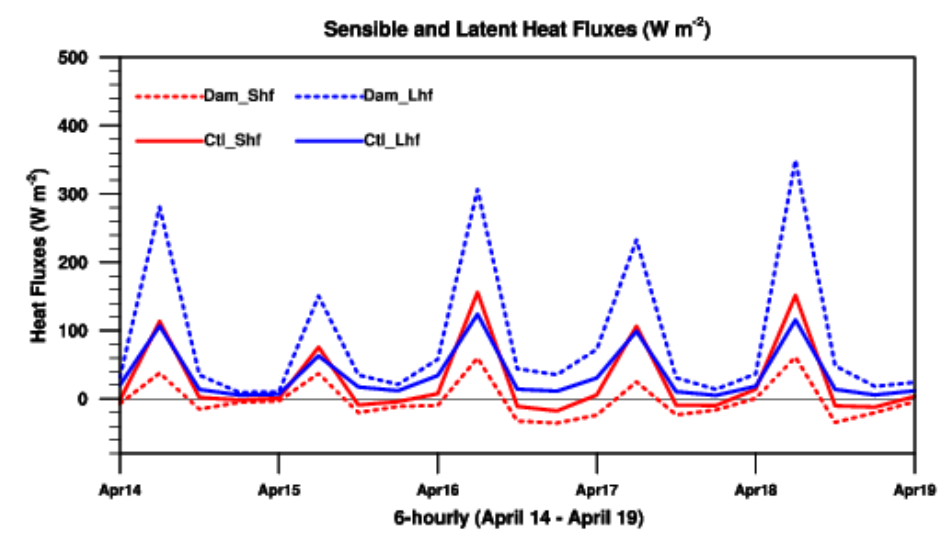

Figure 4. The diurnal latent and sensible heat fluxes for the control (solid) and change (dashed). 
Diff in the $850 \mathrm{mb}$ Vertical Wind Speed (mm/s) (Dam-Cnt)

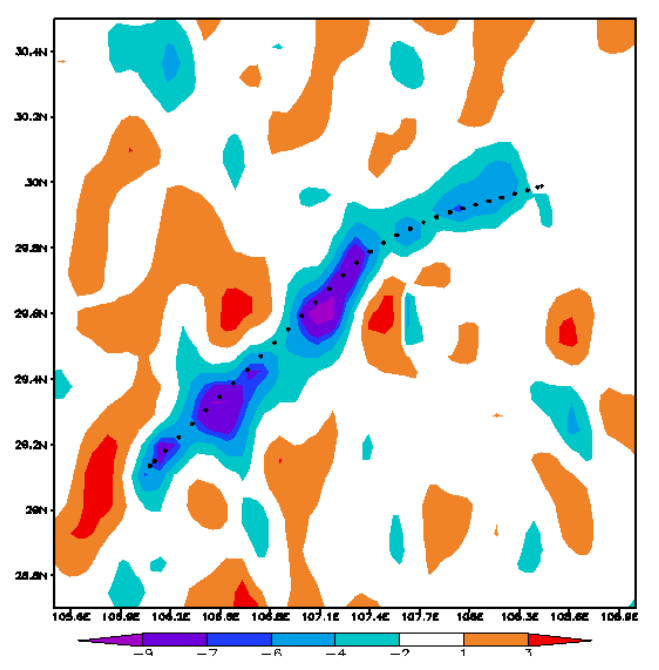

Figure 5. The $850 \mathrm{mb}$ vertical wind speed $(\mathrm{mm} / \mathrm{s})$ difference between the change and control indicates a strong downward flow in the presence of the TGD.

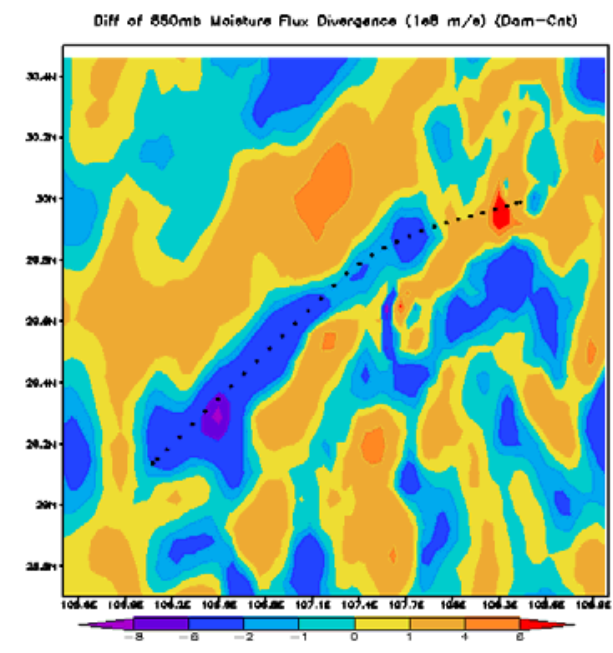

Figure 6. The impact of the sinking air mass is a low level moisture divergence for the TGD case. 


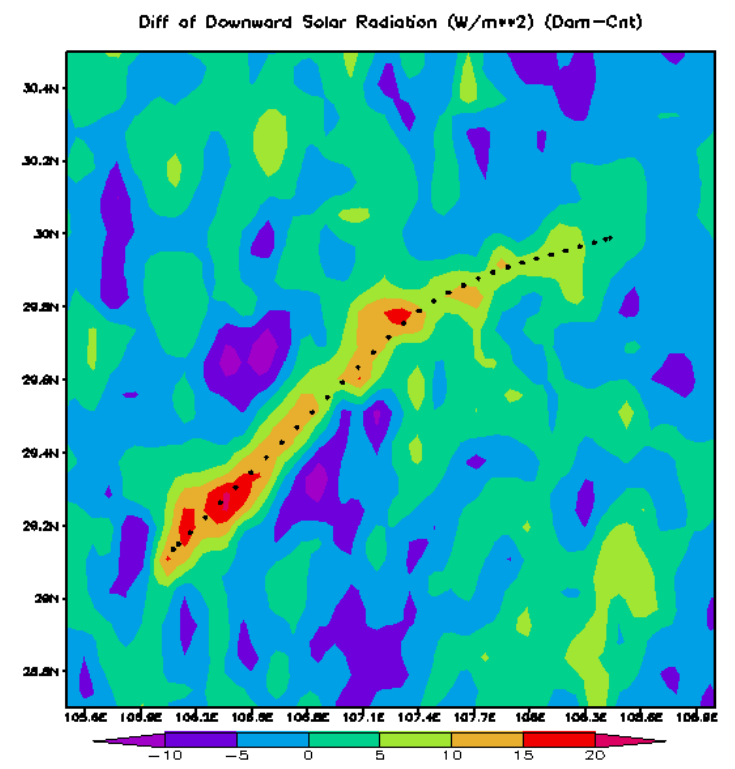

Figure 7. The difference in downward solar radiation with the presence of TGD and without indicated a net increase of $10-25 \mathrm{~W} / \mathrm{m}^{2}$ along the Yangtze River Valley area.

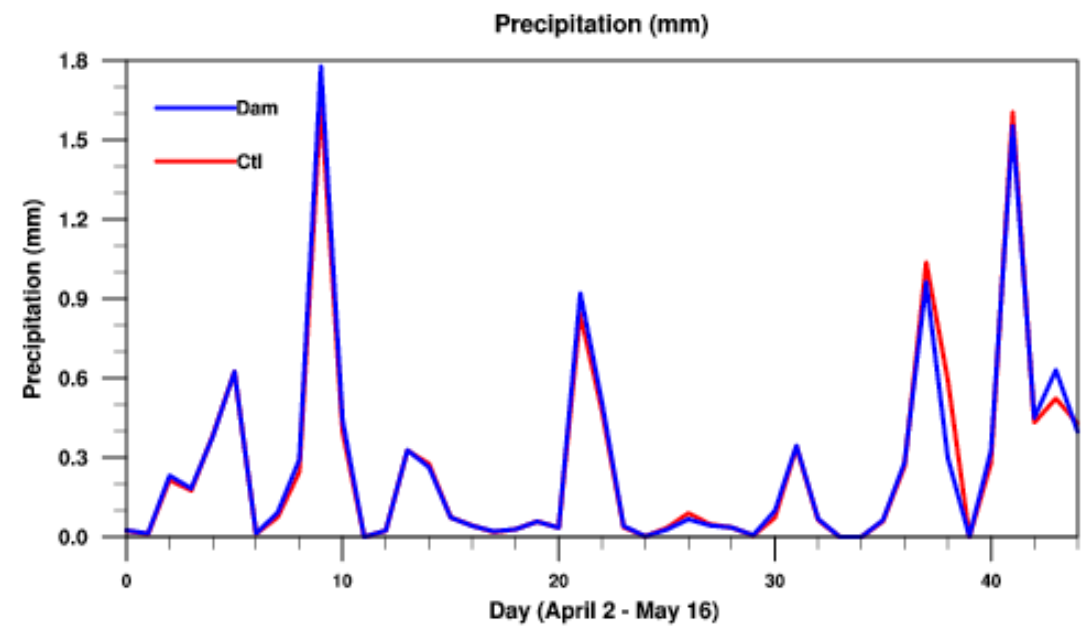

Figure 8 . The moisture divergence results in no precipitation change for the simulated TGD. 